\title{
RhoA Signaling in Immune Cell Response and Cardiac Disease
} Lucia Sophie Kilian ${ }^{1,2}$, Derk Frank ${ }^{1,2, *}$ and Ashraf Yusuf Rangrez ${ }^{1,2,3, *}$

1 Department of Internal Medicine III (Cardiology, Angiology, Intensive Care), University Medical Center Kiel, 24105 Kiel, Germany

2 DZHK (German Centre for Cardiovascular Research), partner site Hamburg/Kiel/Lübeck, 24105 Kiel, Germany

3 Department of Cardiology, Angiology and Pneumology, University Hospital Heidelberg, Heidelberg, Germany

* Correspondence: ashrafyusuf.rangrez@med.uni-heidelberg.de (AYR) derk.frank@uksh.de (DF)

\begin{abstract}
Chronic inflammation, the activation of immune cells and their cross-talk with cardiomyocytes in the pathogenesis and progression of heart diseases has long been overlooked. However, with the latest research developments, it is increasingly accepted that a vicious cycle exists where cardiomyocytes release cardiocrine signaling molecules that spirals down to immune cell activation and chronic state of low-level inflammation. For example, cardiocrine molecules released from injured or stressed cardiomyocytes can stimulate macrophages, dendritic cells, neutrophils and even T-cells, which then subsequently increase cardiac inflammation by co-stimulation and positive feedback-loops. One of the key proteins involved in stress-mediated cardiomyocyte signal transduction is a small GTPase RhoA. Importantly, the regulation of RhoA activation is critical for effective immune cell response and is being considered as one of the potential therapeutic targets in many immune-cell-mediated inflammatory diseases. In this review we provide an update on the role of RhoA at the juncture of immune cell activation, inflammation and cardiac disease.
\end{abstract}

Keywords: RhoA; cardiac inflammation; immune cells; cardiocrine signaling; cardiac diseases

\section{Introduction}

Since Levine et al. reported elevated levels of tumor necrosis factor (TNF) in heart failure (HF) patients, evidence is accumulating that activation of proinflammatory pathways and chronic inflammation play an important role in HF [1,2]. For example, inflated levels of several pro-inflammatory cytokines like TNF $\alpha$, interleukin-1 (IL-1) and IL-6 have been observed in and associated with HF prognosis [2-4]. Mechanistically, increased expression of TNF $\alpha$ and IL-1 $\beta$ leads to cardiomyocyte hypertrophy, likely through induction of transcription factors such as nuclear factor- $\kappa \mathrm{B}(\mathrm{NF}-\kappa \mathrm{B})$ [5-7]. Generation of a proinflammatory milieu characterized by secretion of cytokines, and chemokines further stimulate migration of monocytes and their differentiation into macrophages in the cardiac tissue [8-10]. In turn, the expansion of immune cells promotes pathological tissue remodeling and induces cardiomyocyte apoptosis and ultimately cardiac decompensation [11].

The immune system is based on two main complexes: (1) the innate immune system and (2) the adaptive immune system. The innate immune system is triggered by direct contact with pathogens or inflammatory/danger signals and includes non-cellular responses, i.e. the release of inflammatory cytokines, and cellular responses, i.e. infiltration of innate immune cells (macrophages, dendritic cells, and granulocytes) into affected tissue [12]. The adaptive immune system also involves non-cellular (hormonal) and cellular responses (stimulation of $\mathrm{B}$ - and T-cells), but in contrast to the innate response, it builds up an "immunologic memory" by developing pathogen-specific receptors [12]. RhoA, an ubiquitously expressed small GTPase, acts as a molecular switch not only in the activation of cytoskeletal proteins but also in responding chemokines, cytokines, and growth factors released from both innate and adaptive immune cells [13]. Furthermore, RhoA activation and RhoA-dependent signaling pathways in cardiomyocytes $[13,14]$ and in immune cells 
$[13,15]$ have been shown to mediate immune responses, which play an important role in pathogenesis and progression of cardiac dysfunction [12]. Present review aims at summarizing the possible role RhoA plays in cardiac disease via mediating host immune system and how it can be exploited therapeutically to improve cardiac health of patients.

\section{Links between cardiac hypertrophy, heart failure, and immune cell activation}

In the last decades, the role of the innate and adaptive immune response is being linked with a number of signaling molecules and pathways, including RhoA activation in cardiomyocytes [13]. Furthermore, it has been illustrated that different cardiac diseases (e.g. ischemic, hypertensive, and genetic cardiomyopathies) converge in inducing a common immune response that contributes to disease progression [12] (Figure 1). However, exact causes, underlying mechanisms and signaling pathways of the interplay between cardiac diseases and pro- as well as anti-inflammatory immune system responses are still largely unknown.

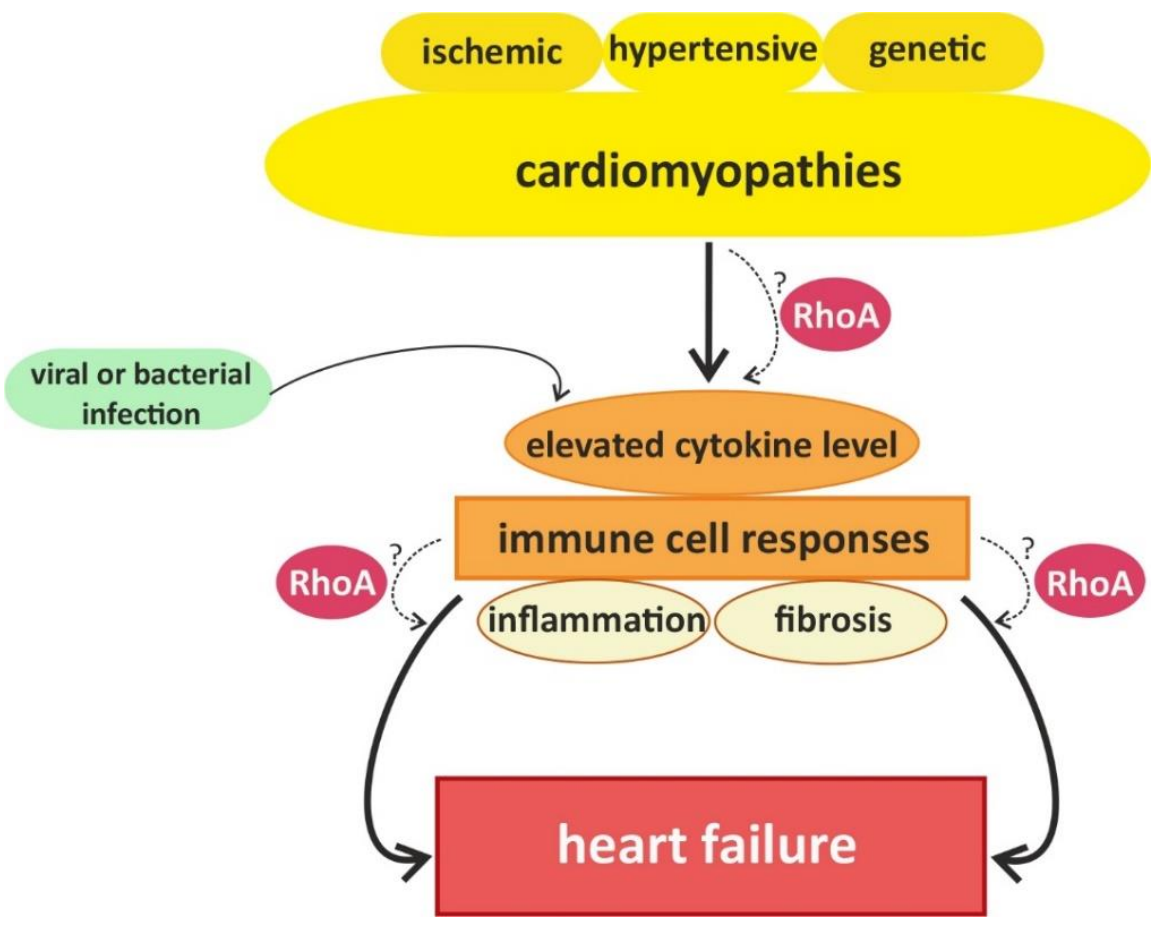

Figure 1: Cardiomyopathies with different causality led to immune cell responses which contribute to the development of heart failure. Besides viral or bacterial infections, ischemic, hypertensive and genetic cardiomyopathies induce an increase in cytokine level, which triggers the activation of immune cells associated with inflammation and fibrosis and thus exacerbates cardiac dysfunction. RhoA-dependent signaling has been suggested to play a role in the enhancement of cytokine level, deleterious inflammatory and fibrotic remodeling and the development of heart failure.

Signals that trigger activation of innate immune cells and subsequent immune responses are pathogen associated molecules or "danger-molecules" and other signals arising from damaged tissue [12]. The main group of receptors for inflammatory signals consists of pattern recognition receptors (PRRs) [12]. PRRs, which are generally upregulated in HF [16], are commonly expressed by immune cells, but have also been found in cardiac cells $[17,18]$, . Although PPRs are best known for their activation after contact with pathogens, it can also be activated by danger-associated molecular patterns (DAMPs) that are released by damaged or dying cells [19], e.g. injured myocardium. The activation of PPRs triggers the release of inflammatory cytokines [20] (e.g. IFN and IL-1 $\beta$ ) and thus accelerate immune responses [12] (Figure 2). 
Natriuretic peptides are key players of cardiac hypertrophy and HF [14]. Brain and atrial natriuretic peptides (BNP and ANP) are part of the "hypertrophic gene program" in cardiomyocytes and their upregulation, which is partly mediated by RhoA activation, is an established marker for cardiac hypertrophy [14,21,22]. In recent years, the function of natriuretic peptides as cytokines and the links between cardiomyocytes and immune cells have come into focus [23]. Immune cells, especially macrophages, have been shown to produce natriuretic peptides and expresses their receptors [23]. In vitro experiments demonstrated that inflammatory cytokines like TNF and IL-1 $\beta$ upregulate BNP in cardiomyocytes [24], whereas ANP can reduce the activation of $\mathrm{NF} \kappa \mathrm{B}$, thus reducing TNF-induced infiltration by neutrophils [25-27]. So, the upregulation of "hypertrophic gene program" might induce a feedback loop attenuating inflammation [12]. However, more studies are needed to understand the links between hypertrophic signaling pathways in cardiomyocytes and immune cell responses.

The best studied immune cells in the context of cardiomyopathies are macrophages. In general, two classes of macrophages are defined: (1) classically activated macrophages (=M1), which correlated with pro-inflammatory processes and (2) alternatively activated macrophages (=M2) correlating with anti-inflammatory processes. Most macrophages found in damaged (cardiac) tissue originate from myeloid naïve monocytes, which circulate in the blood stream, migrate into affected tissue, and differentiate after activation, which belong to the M1 class [28]. In addition, one subclass of macrophages, called resident macrophages (rcMACs), resides in specific tissues including myocardium under physiological circumstances [28,29]. These residential cardiac macrophages can get activated directly by signals of surrounding (cardiac) cells and belong to the M2 class [28,29]. In this context RhoA-signaling has been linked to macrophage polarization via its main effector ROCK1 in mice cells [30]. Furthermore, activation of macrophages has been demonstrated to correlate with the progression of cardiac hypertrophy and fibrosis to HF [12,31-33] (Figure 2). For HFpEF (heart failure with preserved ejection fraction), which is initially characterized by hypertrophy followed by cardiac fibrosis and left ventricular dysfunction, the involvement of (innate) immune responses, and especially, activation of macrophages has been described [12]. Cardiac (resident) macrophages have been shown to induce cardiomyocyte death and fibrosis during HFpEF [34]. In addition, enhanced numbers of monocytes in the blood and activation of M2-type macrophages have also been shown to correlate with left ventricular dysfunction and progression of HFpEF [35]. Dilated cardiomyopathy (DCM) caused by congenital mutations and manifested as dysfunction of the left ventricle has also been associated with activation of immune responses [31].

It has been suggested that pro-inflammatory signals in hypertrophic hearts generated by injured myocardium induce differentiation of circulating monocytes to pro-inflammatory M1-type macrophages and even induce pro-inflammatory responses in residential macrophages, enhancing disease progression [31,32]. In addition, an increase in M2-type macrophage polarization in the heart has been linked to progression of hypertrophy to $\mathrm{HF}$, because the anti-inflammatory responses are known to induce fibrosis [12]. However, treatment with the anti-inflammatory cytokine IL-10 in mice has been shown to block cardiomyocyte hypertrophy and fibrosis induced by pressure overload or hormonal stimulation [36]. Overall, inflammation in cardiac tissue correlates with higher numbers of macrophages in the cardiac tissue, but the origin of these macrophages (resident or infiltrating), their polarization (M1 or M2) and their effect (pro or contra disease-progression), as well as the exact role of RhoA signaling is still under discussion.

Besides macrophages, dendritic cells (DCs) and neutrophils are the main actors of the innate immune response system. DCs are derived from myeloid progenitors and are located in tissues with contact to the external environment and in the blood. Upon activation they migrate to lymph nodes, generate and present specific antigen complexes and so activate B and T-cells. DCs have been found in cardiac tissue injured by cardiac infarction and there is some evidence that they are involved in the subsequent cardiac remodeling $[37,38]$. In this context a beneficial effect of DC activation in the heart by regulation of 
monocyte/macrophage homeostasis has been suggested [38]. In contrast, DCs might also promote the development and progression of cardiac hypertrophy and HF [39,40]. Recruitment of T-cells, which is generally induced by stimulation of DCs, has been shown to promote the transition from cardiac hypertrophy to HF in TAC-operated mice $[39,40]$. However, no detailed studies on the activation and function of DCs in cardiac hypertrophy are published up to now. Neutrophils are also myeloid cells and the most abundant class of granulocytes. They are best known for their role in anti-bacterial responses. Moreover, neutrophils which are located in blood vessel walls can become activated by biomechanical (shear-)stress and in response to inflammatory signals, migrate into the affected tissue, and release more inflammatory signals inducing cell death and/or co-stimulation of other immune cells $[12,41]$. There is some evidence that neutrophils also play a role in cardiac remodeling after infarction, as depletion of neutrophils in mice reduced reperfusion-induced necrosis [42] (Figure 2). However, elaborate research on the role of neutrophil activation in cardiomyopathies is still missing.

Data on links between cells of the adaptive immune system (T- and B- cells) and cardiac diseases, especially hypertrophy, is also insufficient. As mentioned above, there is some evidence that recruitment of T-cells enhances the progress of TAC-induced cardiac hypertrophy $[39,40]$. Furthermore, mice with depletion of T-cells exhibit lower number of infiltrating macrophages, reduced fibrosis and reduced cardiac dysfunction after TAC [39]. Nevertheless, more studies are needed to identify interconnections of hypertrophic cardiomyocytes and activation of T- and/or B-cells.

Taken together, there is some evidence for links between cardiac hypertrophy and immune system responses. An overlap of risk factors for cardiomyopathies and (chronic) inflammation as well as the activation of immune cells in a variety of cardiac diseases are promising fields for further research, as is the postulated interplay of upregulation of hypertrophic markers (BNP and ANP) and cytokine signaling [23-27]. 


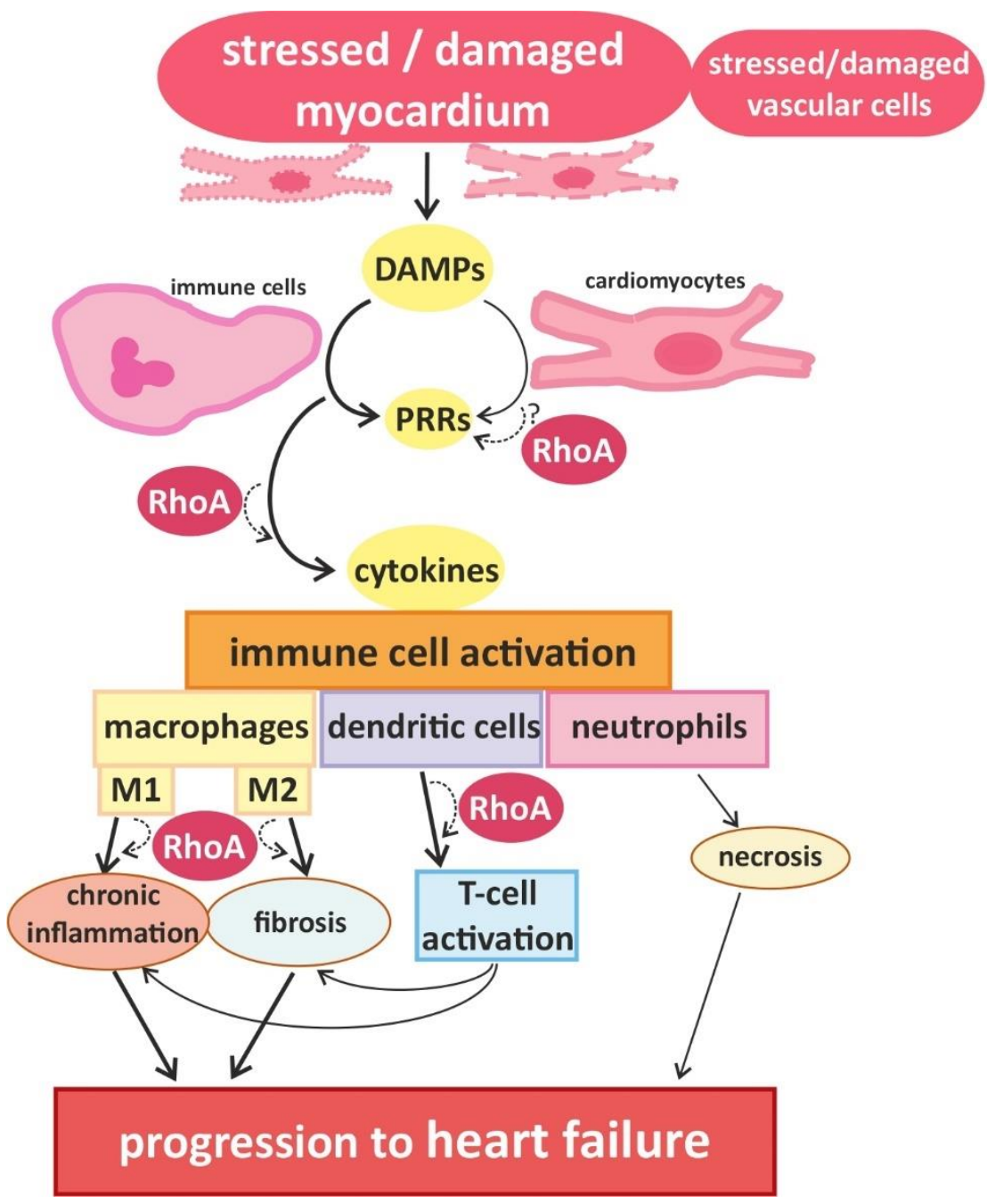

Figure 2: Danger signals released by cardiovascular cells activate immune cells and promote heart failure. Cardiomyocytes and blood vessel cells that are stressed or injured release danger signals with "danger-associated molecular patterns" (DAMPs), which are recognized by "pattern recognition receptors" (PRRs), expressed by immune cells and cardiomyocytes. The activation of PRRs induces the migration and activation of (more) immune cells via cytokine signaling. In damaged myocardium M1-type and M2-type macrophages are found, which are associated with chronic inflammation and fibrosis, respectively. Furthermore, dendritic cells and costimulated T-cells contribute to the development of inflammatory and fibrotic remodeling. Infiltrating neutrophils are associated with increased necrosis. These processes accelerate the progression of cardiac dysfunction. RhoA-dependent signaling is essential for effective immune cell activation and might also play a role in the transduction of danger signals and receptor activation in cardiomyocytes. In addition RhoA-signaling is involved in macrophage polarization and signaling pathways mediating the interaction between dendritic cells and T-cells, contributing to pro- and anti-inflammatory remodeling and finally heart failure.

\section{RhoA activation and signaling in immune cells}

Recent studies demonstrate that RhoA plays an important role in immune responses, with its effects being highly depended on the spatio-temporal regulation of RhoA activation in different innate and adaptive immune cells [13]. On molecular level, the activation of RhoA in immune cells and cardiomyocytes is regulated by regulatory proteins, namely GEFs (guanine nucleotide exchange factors), GAPs (GTPase activating proteins), GDIs (guanine nucleotide 
dissociation inhibitors) and GDFs (GDI dissociation factors) [13,22]. A number of these regulators have been shown to be identical in immune cells and cardiomyocytes (e.g. LARGRhoGEF, Lfc/GEF-H1, PDZ-RhoGEF, p190RhoGAP, and Vav1) [41,43], while others were found specifically in immune cells (e.g. RhoA-GAP-Myo9B and GEF-ARHGEF7) [44]. Even some of the up- and downstream signaling pathways of RhoA described in cardiomyocytes have been proven to play an important role in immune cells, too (e.g. RhoA activation via Ga12/13coupled membrane receptors [45-47] and RhoGEF or activation of the RhoA effector ROCK $[13,15,45-48]$. The processes affected by RhoA in the context of immune responses are basic cellular processes such as cytoskeletal arrangement, mobility, cell-cell contact, cell-cycle regulation, proliferation and cell survival, as well as directed migration and (co-)stimulation of immune cells [13] (Error! Reference source not found. and

(A) T-cells

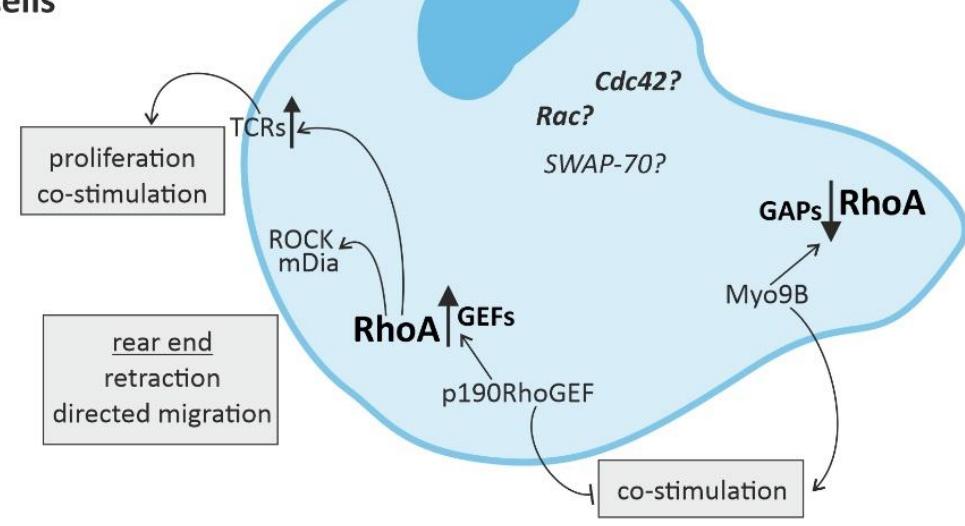
protrusion

(B) B-cells

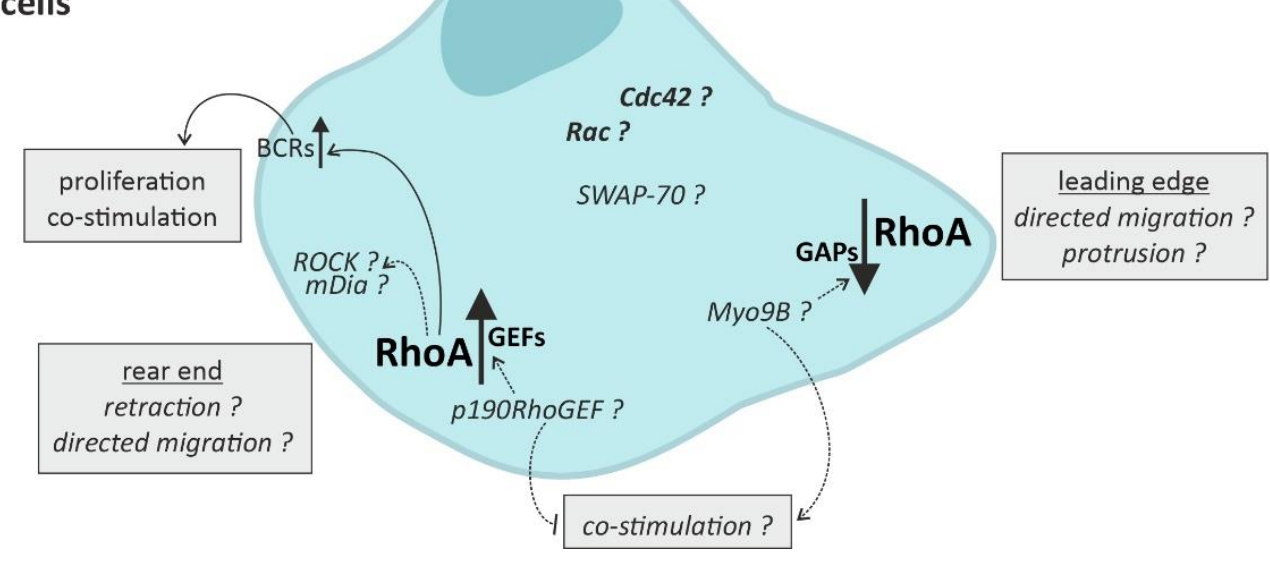

Figure 4).

\subsection{RhoA activation in macrophages, dendritic cells and granulocytes}

In macrophages, DCs and granulocytes, it has been shown that in general RhoA activation in the rear end (uropod) [15] and RhoA inhibition in the leading edge (podosome, pseudopod) [15,44] is essential for directed migration [13] (Error! Reference source not found.A-C). However, a number of experiments have demonstrated that the spatio-temporal regulation of RhoA activation in the immune cells is essential for effective immune responses [13]. At the leading edge of macrophages, RhoA is inhibited by the Rho-GAPs Myo9B and p120RhoGAP which in turn are up-regulated by Krüppel-like factor-5 (KLF- 
5) and the B-cell lymphoma-6 (Bcl-6) molecule via the macrophage colony stimulating receptor 1 (CSF1), respectively [49]. Consistently, knockout of Myo9B as well as inhibition of Bcl-6 led to upregulation of active RhoA in macrophages [50,51]. In accordance with the importance of spatio-temporal regulation of RhoA, the directed migration of the macrophages was impaired in both experiments [50,51]. The activation of RhoA at the uropod was stimulated by pro-inflammatory cytokine tumor necrosis factor alpha (TNF- $\alpha$ )-induced signaling via PI3K and the Rho-GDF ERM [52]. RhoA activated the downstream effectors ROCK and mDia facilitating the retraction of the rear end [52]. Treatment with the anti-inflammatory cytokine TGF- $\beta 1$ first induced the RhoA activation at the rear end, but over time inhibited it via activation of protein kinase A (PKA) and p190RhoGAP [53] (Error! Reference source not found.A).

RhoA activation in the rear end of DCs with the consecutive activation of ROCK and $\mathrm{mDia}$, as well as RhoA inhibition by Myo9B have also been suggested as essential signaling pathways for their cytokine-induced directed migration [13,54,55]. Myo9B knockout mice had lower levels of active RhoA in the DCs and impaired directed migration, similar to the findings in macrophages $[50,56]$. RhoA and mDia have been found to be enriched in the rear end of immature motile mice DCs in vitro [54] and in vivo inhibition of ROCK in mice skin DCs impaired their migration [57]. Likely time-dependent activation of RhoA and crosstalk with other Rho-family protein signaling pathways also play a role here, as Cdc42 was enriched in the front end of mice DCs in vitro [54]. Knockout of the RhoAinhibiting and Rac activating protein SWAP-70 (switch-associated protein 70) [58] interfered with the distribution of the small GTPases Cdc42, Rac, and RhoA and lead to increased RhoA level, which impaired directed migration and attenuated retraction of the rear end in response to cytokine stimulation [59]. However, DCs with knockout of the Rho-GEF ARHGEF5 and consequently reduced RhoA level also exhibited impaired migration in vitro and in vivo [55] (Error! Reference source not found.B).

In neutrophils Cdc42 and Rac were found at the leading edge and activated RhoA at the rear end, too [13]. Upregulation of RhoA in the rear end of neutrophils was associated with upregulation of RhoGEFs (e.g. PDZ-RhoGEF, LARG-RhoGEF, Lsc/p115RhoGEF, and Lfc/GEF-H1) which was in part linked to G $12 / 13$-coupled receptor activation and lead to RhoA-induced accumulation of ROCK and $\mathrm{mDia}$ which is needed for retraction of the rear end and directed migration [13] (Error! Reference source not found.C). 


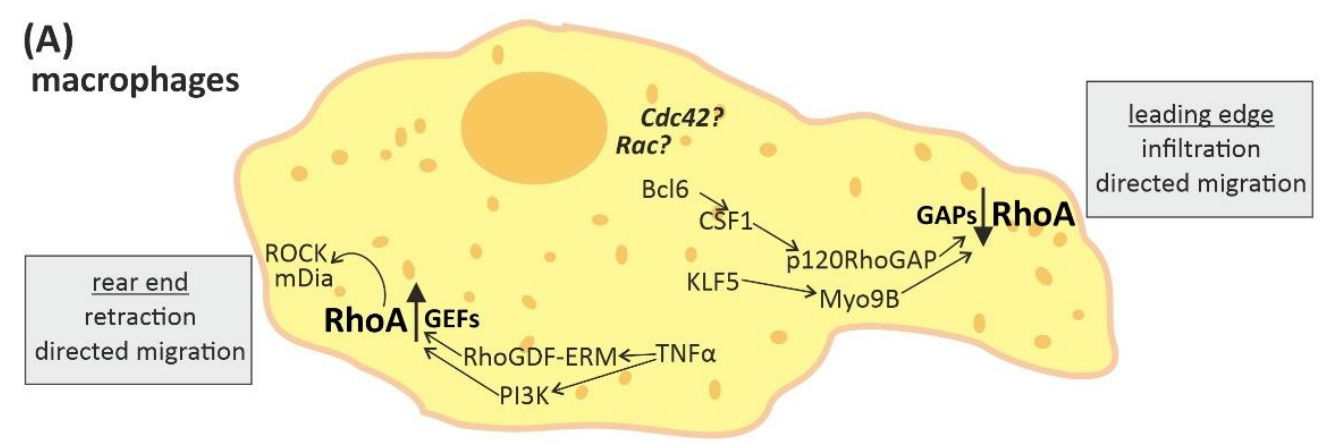

(B) dendritic cells

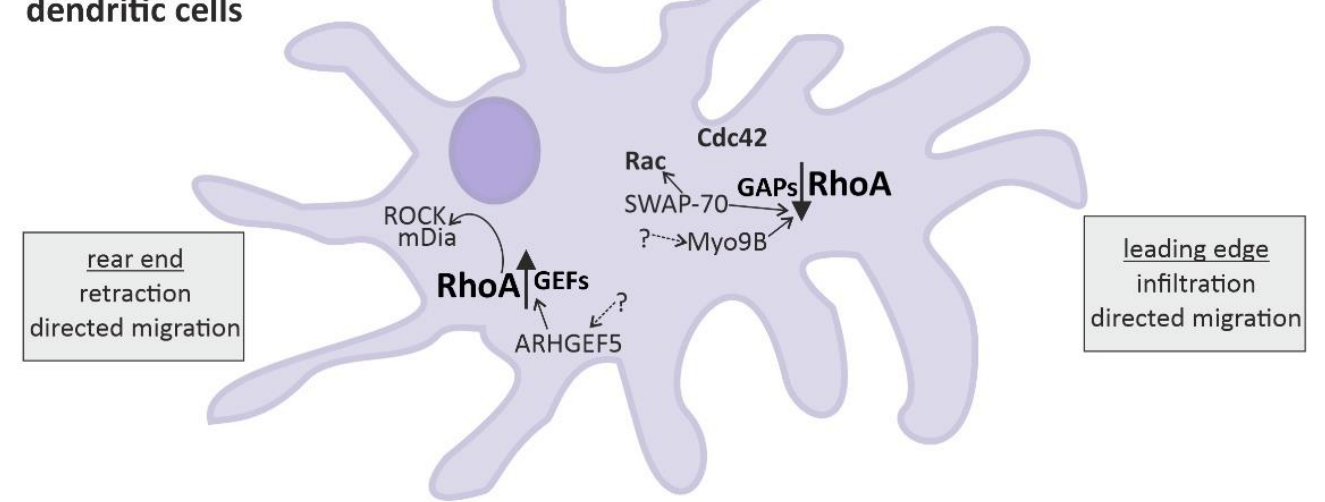

(C)

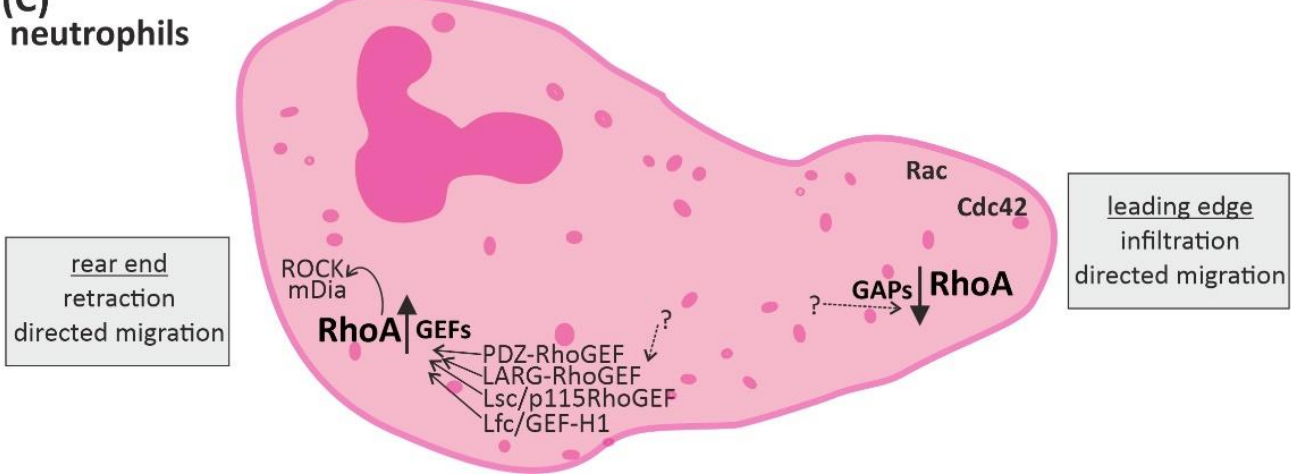

Figure 3: RhoA-signaling plays an important role in cells of the innate immune system. Directed migration of macrophages, dendritic cells, and neutrophils is mediated by spatio-temporal regulated RhoA-activation. In general, RhoA is activated in the rear end and reduced in the leading edge. The up-regulation of RhoA is mediated by "guanine nucleotide exchange factors" (GEFs) and leads to activation of the downstream effectors ROCK and mDia, which promote retraction of the rear end. RhoA-downregulation is mediated by "GTPase activating proteins" (GAPs) and facilitates infiltration or protrusion. Some signaling molecules up- and downstream of RhoA-activation have been identified in different immune cells. However, many aspects of the signaling pathways are not fully known yet (indicated by dotted arrows and question marks). (A) In macrophages some regulators of RhoA have been identified. KLF5 and CSF1 activation via Bcl6 lead to activation of the RhoA-GAPs Myo9B and p120RhoA, respectively, reducing RhoA-activation at the front. Contrarily, RhoGDF-ERM and PI3K promote the activation of RhoA at the end. (B) In dendritic cells Myo9B is also located at the leading edge, attenuating RhoA-activation, while ARHGEF5 is found in the rear end, promoting RhoAactivation. Furthermore, SWAP-70 was identified as a regulator of small GTPase activity. (C) In neutrophils a number of GEFs facilitating RhoA activation have been identified. In addition the small GTPases Rac and Cdc42 are located close to the leading edge. 


\subsection{RhoA activation in T-cells and B-cells}

The effect of RhoA expression in cells of the adaptive immune system is also highly controlled in a spatio-temporal manner [13]. Pollock et al. have shown that RhoA-induced ROCK/mDia activation in the uropod of T-cells is essential for their directed migration, as in innate immune cells

[60]

(A) T-cells

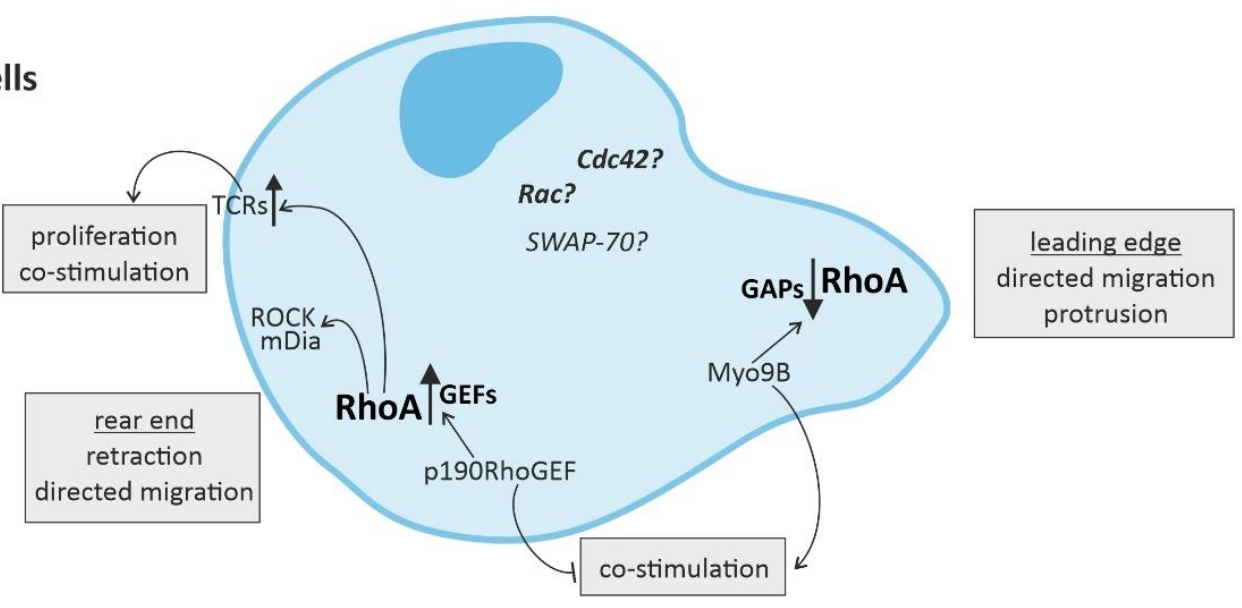

(B) B-cells

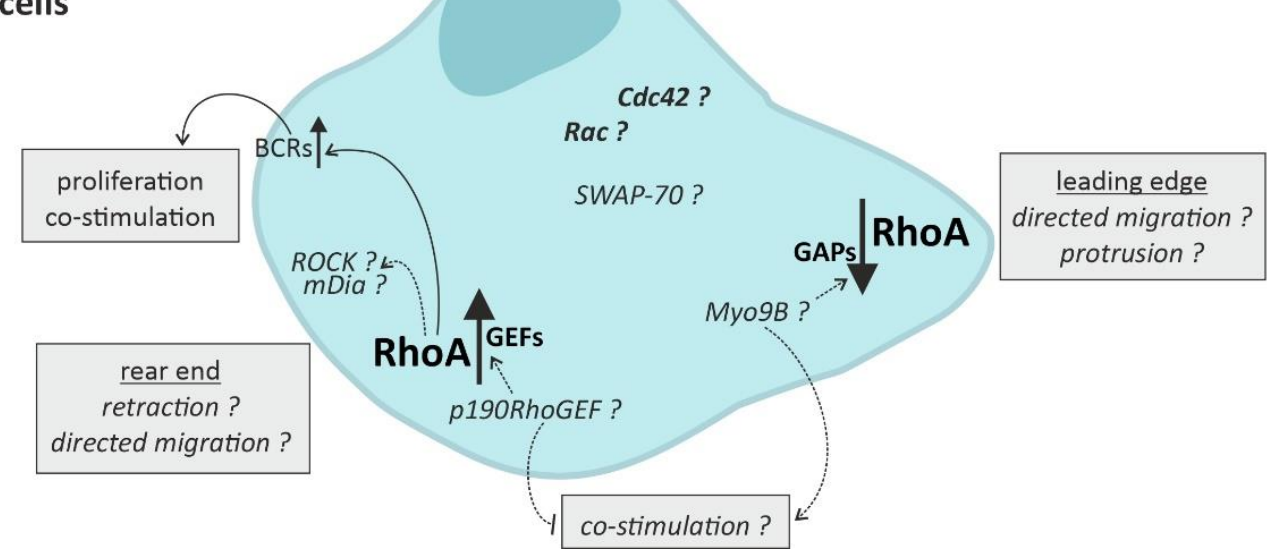

Figure 4A). Similarly, inhibition of RhoA by the Rho-GAP Myo9B in the leading edge was also shown to be needed for directed migration of T-cells [13,61]. Consistently, depletion of Myo9B in T-cells lead to increased RhoA activation causing impaired directed migration, as described for innate immune cells, and attenuated protrusion through extracellular matrix [61]. However, other in vitro experiments proved that time-dependent regulation of RhoA activation in T-cells is essential [13], as after infiltration into injured tissue the RhoA downstream effector mDia was found to be increased in the leading edge of activated T-cells $[62,63]$.

In addition to migration, RhoA has been shown to play an important role in T-cell-associated (co-)stimulation of immune cells $[13,64]$. The knockout of the RhoA-GAP Myo9B in mice, enhancing RhoA activation, did not only impair migration of innate and adaptive immune cells, but also affected DC/T-cell contact and reduced T-cell proliferation [13]. Knockout of SWAP-70 in DCs, also enhancing RhoA activation, led to reduced expression of the pro-inflammatory CD4 ${ }^{+}$-T-cell stimulatory surface marker MHC-II [65], but increased presentation of the anti- 
inflammatory CD8 ${ }^{+}-\mathrm{T}$-cell stimulatory marker MHC-I [66]. Consistently, mice overexpressing p190RhoGEF, which is associated with increased RhoA activation, showed defective costimulation

capacity

of

T-cells

[59]

(A) T-cells

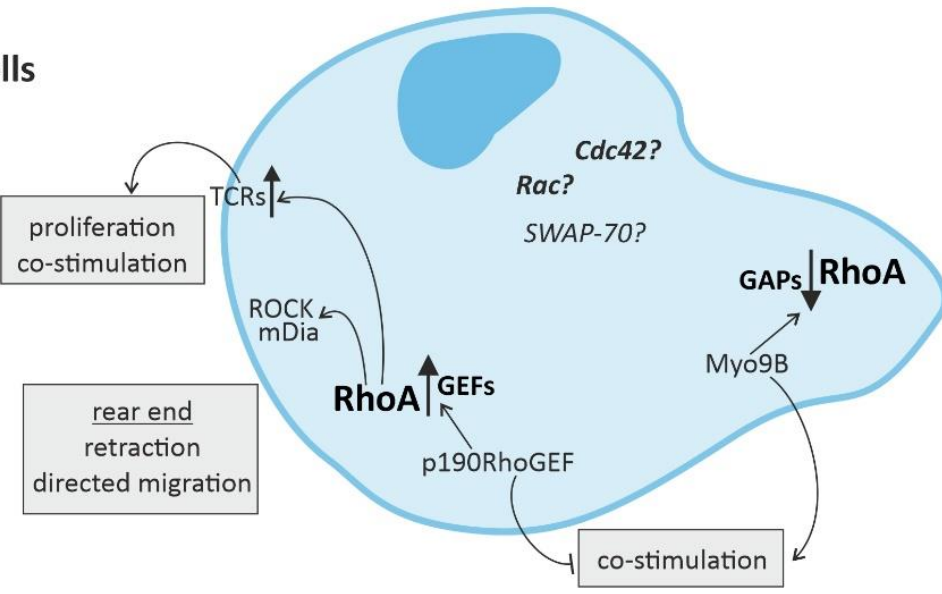

leading edge directed migration protrusion

(B)

B-cells

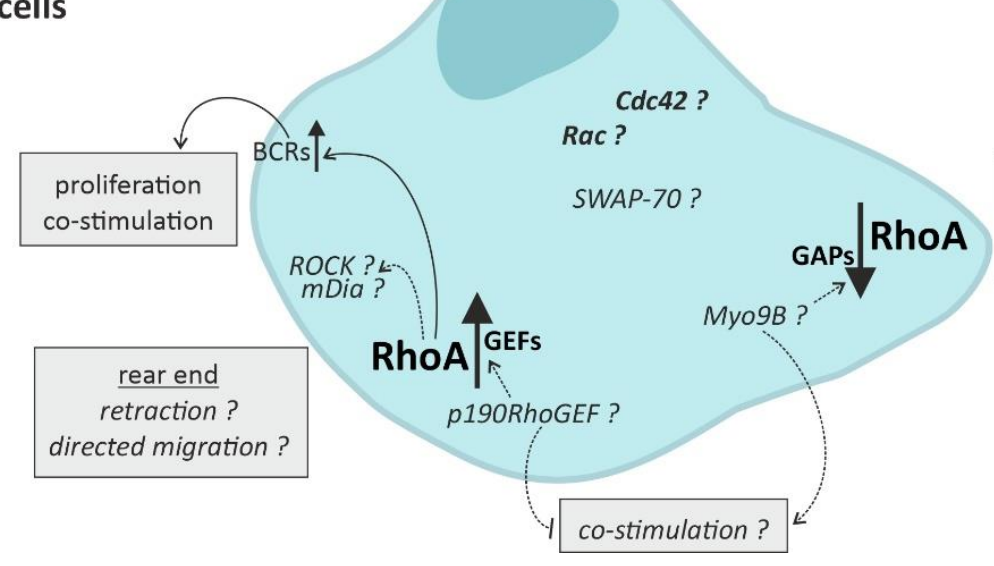

leading edge directed migration ? protrusion?

Figure 4A). RhoA activation is associated with T-cell receptors (TCRs), which recognize $\mathrm{MHC} /$ antigen complexes presented at the surface of other cells and induce a variety of downstream signaling, leading to co-stimulation of other immune cells and enhancement of pro-inflammatory signaling [13]. However, Rho-GEF Vav1 was shown to get activated by TCR activation and function as part of a negative feedback loop, reducing the TCR-induced co-stimulation $[67,68]$. In addition, RhoA was shown to compromise the expression of pro-inflammatory and co-stimulating cytokine IL-2 by T-cells [69].

Like its function in T-cells, RhoA activation in B-cells has been linked to B-cell receptor (BCR) activation and B-cell proliferation [13,70]. RhoA downregulation attenuated B-cell proliferation induced by BCR-activation [70]. Furthermore, B-cell activation depends on CD4 ${ }^{+}$- 
(A) T-cells

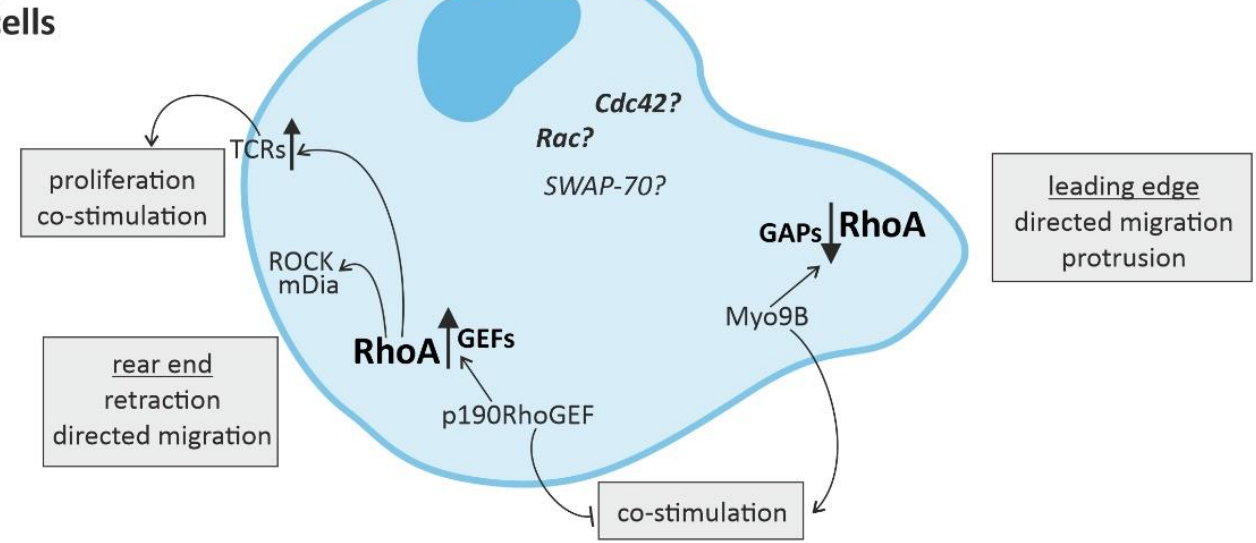

(B) B-cells

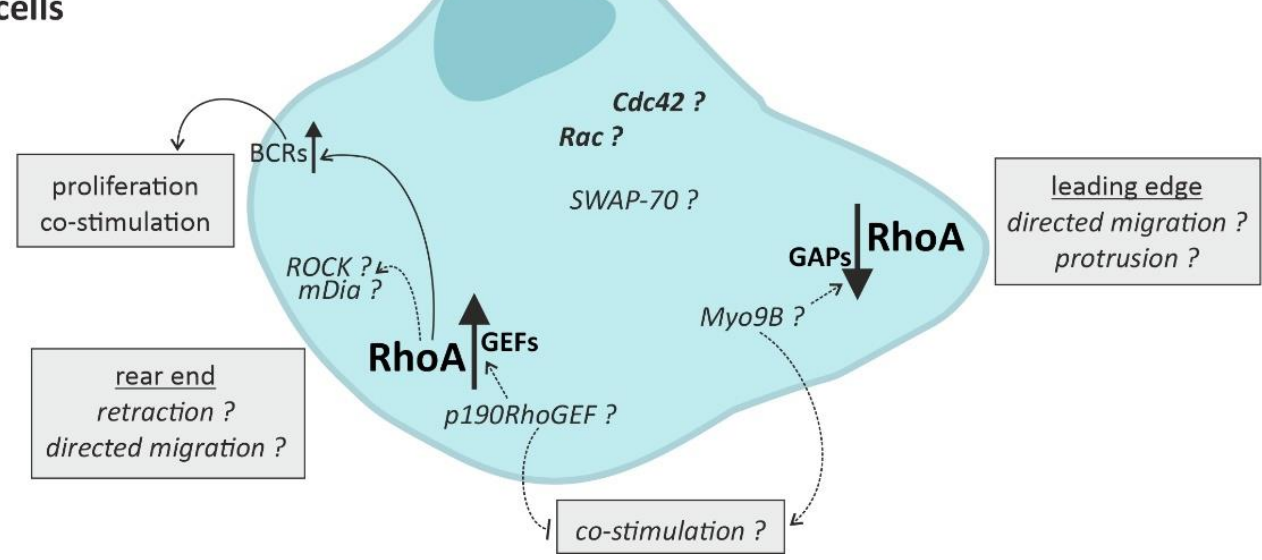

Figure 4B). On the one hand this activation has been associated with increased RhoA expression via p190RhoGEF [13]. On the other hand, as described above, RhoA has been suggested to induce downregulation of CD4+/MHC-II stimulation [65]. This might represent another negative feedback loop. 


\section{(A)} T-cells

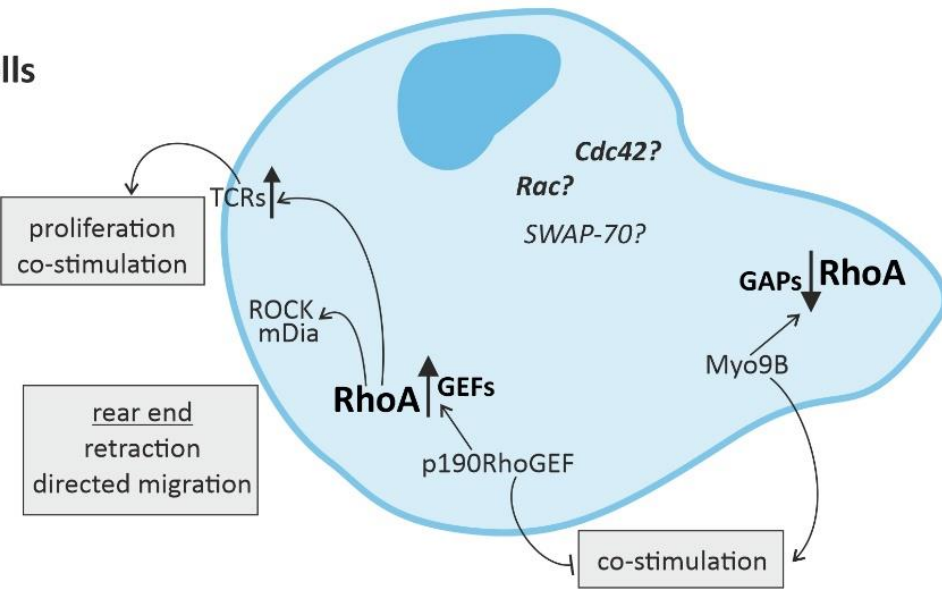

leading edge directed migration protrusion

(B) B-cells

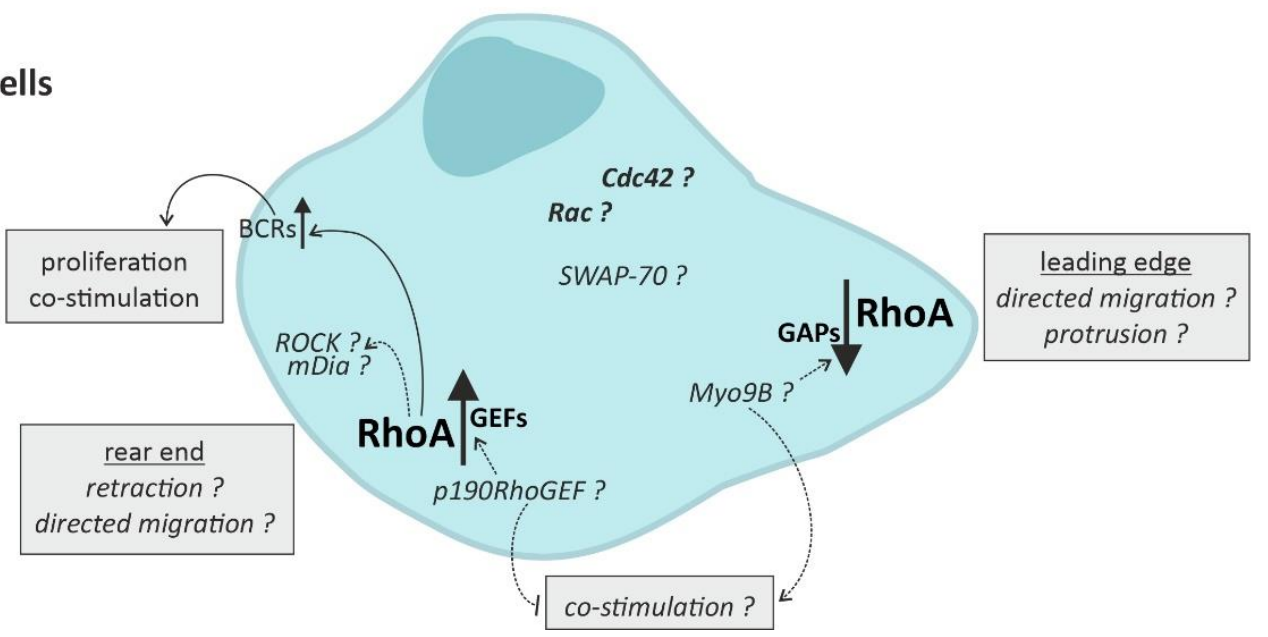

Figure 4: RhoA-signaling in cells of the adaptive immune system. Directed migration of T- and Bcells is regulated by spatio-temporal activation of RhoA, with mainly rhoA activation in the rear end and RhoA downregulation in the leading edge.(A) In T-cells RhoA-activation in the rear end not only leads to retraction via ROCK and mDia, but is also associated with the promotion of $\mathrm{T}$ cell receptor (TCR) activity, inducing T-cell proliferation and co-stimulation of more immune cells. (B) It is suggested that RhoA-signaling in B-cells involves proteins and processes, similar to those already described for T-cells, such as the induction of proliferation and co-stimulation via promotion of B-cell receptor (BCR) activity, but little has been ascertained in B-cells yet.

Taken together, in vitro and in vivo experiments have demonstrated that RhoA is a key player of immune cell responses, influencing the migratory and stimulatory capacity of innate and adaptive immune cells [13]. In general, RhoA upregulation in the rear end and RhoA inhibition in the leading edge of innate und adaptive immune cells is necessary for their directed migration. However, an important aspect is the spatially and temporally strictly controlled regulation of RhoA activation, to allow effective immune responses [13]. Further research is needed to unravel the complex regulation and effects of RhoA activation in immune cells and the impact on immune responses linked to cardiac diseases.

\section{Perspectives}


The above-described correlations between immune cell activation and the development and progression of cardiac diseases, are promising starting points for further research.

By analyzing the up- und downstream pathways of RhoA activation in different cells of the innate and adaptive immune system, more mediators of RhoA signaling could surely be identified and more regulatory mechanisms of immune cell responses be described. Important is in this context to pay heed to the spatio-temporal regulation, to get valid and comparable data (e.g. before or after final differentiation or infiltration and localization at the rear or front side).

Another interesting approach to gain more insight into the role of RhoA in the development and progression of cardiac diseases and immune system responses would be large-scale screens for correlations between mutations in the human RhoA-gene and the development of cardiac and/or immune cell-related diseases. Up to now, there are no RhoA mutations corresponding with cardiac diseases known yet, but there is good evidence for direct correlations between mutations of the RhoA-gene as well as known mediators of RhoA signaling pathways and cancer. The mutation RhoA-G17V is common in CD4+ T-cells in lymphomas lymphomas [71] and is associated with autoimmunity, hyperresponsiveness of T-cells and excessive TCR signaling via Vav1 [72]. Also, a gain-of-function mutation of Vav1 itself has been shown to be over-represented in T-cell lymphoma [72].

Vav1 inhibition using dasatinib, which is already used against leukemia [73], reduces TCR-stimulation in lymphoma cells [72]. Accordingly, Vav1-inhibition using dasatinib is a promising tool to impair RhoA activation in cardiomyocytes and immune cells, thus attenuating inflammatory processes which promote the progression of cardiac dysfunction. In addition, statins are known to be effective inhibitors of RhoA-dependent signaling [74] further research could lead to new therapeutic approaches for cardiac diseases.

However, specificity is the key factor in all approaches using inhibitors and more research is needed to analyze potentially beneficial effects of RhoA-inhibition in immune cells and cardiomyocytes and detect off-target effects, for example on Rac or Cdc42.

Further analysis of the links between the release of danger signals by injured, or even just stressed, cardiomyocytes with subsequent cytokine-induced immune cell activation might lead to the identification of new circulating molecules, which can be used as markers for the extend of myocardial stress and damage.

\section{Conclusion}

Taken together, the existing data on the interplay of cardiomyocytes and immune cells, demonstrates good evidence for links between cardiomyocyte damage, immune cell activation and progression of cardiac dysfunction. The intercellular signaling involved in and affected by the development and progression of cardiac diseases includes cardiomyocytes, cells of the innate and adaptive immune system, and other cells present in the myocardium (e.g. fibroblasts). The summary of the data has pointed out that in the intracellular signaling RhoA is one of the key mediators. Regulation of RhoA activation and RhoA-dependent downstream signaling plays an important role in cardiomyocytes and immune cells. The data on effects of RhoA activation and inhibition is often contradictory, depending on specific cell types, spatial, and temporal regulation. For further research, induction of immune cell responses should be considered when analyzing mechanism of the development and progression of cardiomyocyte damage and cardiac dysfunction.

\section{Supplementary Materials: Not applicable}

Author Contributions: Conceived and designed the article: DF and AYR; Wrote the manuscript: LSK, and AYR; Revised the manuscript: LSK, DF and AYR. All authors have read and agreed to the published version of the manuscript.

Funding: This research was funded by the German Research Foundation (DFG) Grant RA2717/2-1 to AYR and the grant from DZHK (German Centre for Cardiovascular Research) to DF. 


\author{
Institutional Review Board Statement: Not applicable \\ Informed Consent Statement: Not applicable \\ Data Availability Statement: Not applicable \\ Acknowledgments: Not applicable
}

Conflicts of Interest: The authors declare no conflict of interest. The funders had no role in the design of the study; in the collection, analyses, or interpretation of data; in the writing of the manuscript, or in the decision to publish the results.

\title{
References:
}

1. Dick, S.A.; Epelman, S. Chronic Heart Failure and Inflammation: What Do We Really Know? Circ Res 2016, 119, 159-176, doi:10.1161/CIRCRESAHA.116.308030.

2. Levine, B.; Kalman, J.; Mayer, L.; Fillit, H.M.; Packer, M. Elevated circulating levels of tumor necrosis factor in severe chronic heart failure. N Engl J Med 1990, 323, 236-241, doi:10.1056/NEJM199007263230405.

3. Mann, D.L. Innate immunity and the failing heart: the cytokine hypothesis revisited. Circ Res 2015, 116, 1254-1268, doi:10.1161/CIRCRESAHA.116.302317.

4. D'Elia, E.; Vaduganathan, M.; Gori, M.; Gavazzi, A.; Butler, J.; Senni, M. Role of biomarkers in cardiac structure phenotyping in heart failure with preserved ejection fraction: critical appraisal and practical use. Eur J Heart Fail 2015, 17, 1231-1239, doi:10.1002/ejhf.430.

5. Thaik, C.M.; Calderone, A.; Takahashi, N.; Colucci, W.S. Interleukin-1 beta modulates the growth and phenotype of neonatal rat cardiac myocytes. J Clin Invest 1995, 96, 1093-1099, doi:10.1172/JCI118095.

6. Yokoyama, T.; Nakano, M.; Bednarczyk, J.L.; McIntyre, B.W.; Entman, M.; Mann, D.L. Tumor necrosis factor-alpha provokes a hypertrophic growth response in adult cardiac myocytes. Circulation 1997, 95, 1247-1252.

7. Purcell, N.H.; Tang, G.; Yu, C.; Mercurio, F.; DiDonato, J.A.; Lin, A. Activation of NF-kappa B is required for hypertrophic growth of primary rat neonatal ventricular cardiomyocytes. Proc Natl Acad Sci $U$ S A 2001, 98, 6668-6673, doi:10.1073/pnas.111155798.

8. Patel, B.; Bansal, S.S.; Ismahil, M.A.; Hamid, T.; Rokosh, G.; Mack, M.; Prabhu, S.D. CCR2(+) Monocyte-Derived Infiltrating Macrophages Are Required for Adverse Cardiac Remodeling During Pressure Overload. JACC. Basic to translational science 2018, 3, 230-244, doi:10.1016/j.jacbts.2017.12.006.

9. Weisheit, C.; Zhang, Y.; Faron, A.; Kopke, O.; Weisheit, G.; Steinstrasser, A.; Frede, S.; Meyer, R.; Boehm, O.; Hoeft, A., et al. Ly6C(low) and not Ly6C(high) macrophages accumulate first in the heart in a model of murine pressure-overload. PloS one 2014, 9, e112710, doi:10.1371/journal.pone.0112710.

10. Liao, X.; Shen, Y.; Zhang, R.; Sugi, K.; Vasudevan, N.T.; Alaiti, M.A.; Sweet, D.R.; Zhou, L.; Qing, Y.; Gerson, S.L., et al. Distinct roles of resident and nonresident macrophages in nonischemic cardiomyopathy. Proc Natl Acad Sci U S A 2018, 115, E4661E4669, doi:10.1073/pnas.1720065115.

11. Kanellakis, P.; Ditiatkovski, M.; Kostolias, G.; Bobik, A. A pro-fibrotic role for interleukin-4 in cardiac pressure overload. Cardiovascular research 2012, 95, 77-85, doi:10.1093/cvr/cvs142.

12. Frantz, S.; Falcao-Pires, I.; Balligand, J.L.; Bauersachs, J.; Brutsaert, D.; Ciccarelli, M.; Dawson, D.; de Windt, L.J.; Giacca, M.; Hamdani, N., et al. The innate immune system in chronic cardiomyopathy: a European Society of Cardiology (ESC) scientific statement from the Working Group on Myocardial Function of the ESC. European journal of heart failure 2018, 20, 445-459, doi:10.1002/ejhf.1138.

13. Bros, M.; Haas, K.; Moll, L.; Grabbe, S. RhoA as a Key Regulator of Innate and Adaptive Immunity. Cells 2019, 8, doi:10.3390/cells8070733.

14. Nakamura, M.; Sadoshima, J. Mechanisms of physiological and pathological cardiac hypertrophy. Nat Rev Cardiol 2018, 15, 387407, doi:10.1038/s41569-018-0007-y.

15. Bodin, S.; Welch, M.D. Plasma membrane organization is essential for balancing competing pseudopod-and uropod-promoting signals during neutrophil polarization and migration. Mol Biol Cell 2005, 16, 5773-5783, doi:10.1091/mbc.e05-04-0358.

16. Frantz, S.; Nahrendorf, M. Cardiac macrophages and their role in ischaemic heart disease. Cardiovascular research 2014, 102, 240248, doi:10.1093/cvr/cvu025.

17. Nishimura, M.; Naito, S. Tissue-specific mRNA expression profiles of human toll-like receptors and related genes. Biol Pharm Bull 2005, 28, 886-892, doi:10.1248/bpb.28.886.

18. Yin, Y.; Yan, Y.; Jiang, X.; Mai, J.; Chen, N.C.; Wang, H.; Yang, X.F. Inflammasomes are differentially expressed in cardiovascular and other tissues. Int J Immunopathol Pharmacol 2009, 22, 311-322, doi:10.1177/039463200902200208.

19. Lin, L.; Knowlton, A.A. Innate immunity and cardiomyocytes in ischemic heart disease. Life sciences 2014, 100, 1-8, doi:10.1016/j.lfs.2014.01.062.

20. Kawai, T.; Akira, S. Toll-like receptors and their crosstalk with other innate receptors in infection and immunity. Immunity 2011, 34, 637-650, doi:10.1016/j.immuni.2011.05.006. 
21. Rangrez, A.Y.; Eden, M.; Poyanmehr, R.; Kuhn, C.; Stiebeling, K.; Dierck, F.; Bernt, A.; Lullmann-Rauch, R.; Weiler, H.; Kirchof, P., et al. Myozap Deficiency Promotes Adverse Cardiac Remodeling via Differential Regulation of Mitogen-activated Protein Kinase/Serum-response Factor and beta-Catenin/GSK-3beta Protein Signaling. The Journal of biological chemistry 2016, 291, 41284143, doi:10.1074/jbc.M115.689620.

22. Kilian, L.S.; Voran, J.; Frank, D.; Rangrez, A.Y. RhoA: a dubious molecule in cardiac pathophysiology. J Biomed Sci 2021, 28, 33, doi:10.1186/s12929-021-00730-w.

23. De Vito, P. Atrial natriuretic peptide: an old hormone or a new cytokine? Peptides 2014, 58, 108-116, doi:10.1016/j.peptides.2014.06.011.

24. Ogawa, T.; Veinot, J.P.; Davies, R.A.; Haddad, H.; Smith, S.J.; Masters, R.G.; Hendry, P.J.; Starling, R.; de Bold, M.K.; Ponce, A., et al. Neuroendocrine profiling of humans receiving cardiac allografts. The Journal of heart and lung transplantation : the official publication of the International Society for Heart Transplantation 2005, 24, 1046-1054, doi:10.1016/j.healun.2004.06.023.

25. Kiemer, A.K.; Weber, N.C.; Furst, R.; Bildner, N.; Kulhanek-Heinze, S.; Vollmar, A.M. Inhibition of p38 MAPK activation via induction of MKP-1: atrial natriuretic peptide reduces TNF-alpha-induced actin polymerization and endothelial permeability. Circulation research 2002, 90, 874-881, doi:10.1161/01.res.0000017068.58856.f3.

26. Mtairag el, M.; Houard, X.; Rais, S.; Pasquier, C.; Oudghiri, M.; Jacob, M.P.; Meilhac, O.; Michel, J.B. Pharmacological potentiation of natriuretic peptide limits polymorphonuclear neutrophil-vascular cell interactions. Arteriosclerosis, thrombosis, and vascular biology 2002, 22, 1824-1831, doi:10.1161/01.atv.0000037102.31086.f4.

27. Chen, W.; Spitzl, A.; Mathes, D.; Nikolaev, V.O.; Werner, F.; Weirather, J.; Spiranec, K.; Rock, K.; Fischer, J.W.; Kammerer, U., et al. Endothelial Actions of ANP Enhance Myocardial Inflammatory Infiltration in the Early Phase After Acute Infarction. Circulation research 2016, 119, 237-248, doi:10.1161/CIRCRESAHA.115.307196.

28. Hulsmans, M.; Sam, F.; Nahrendorf, M. Monocyte and macrophage contributions to cardiac remodeling. Journal of molecular and cellular cardiology 2016, 93, 149-155, doi:10.1016/j.yjmcc.2015.11.015.

29. Sansonetti, M.; Waleczek, F.J.G.; Jung, M.; Thum, T.; Perbellini, F. Resident cardiac macrophages: crucial modulators of cardiac (patho)physiology. Basic Res Cardiol 2020, 115, 77, doi:10.1007/s00395-020-00836-6.

30. Liu, Y.; Minze, L.J.; Mumma, L.; Li, X.C.; Ghobrial, R.M.; Kloc, M. Mouse macrophage polarity and ROCK1 activity depend on RhoA and non-apoptotic Caspase 3. Exp Cell Res 2016, 341, 225-236, doi:10.1016/j.yexcr.2016.02.004.

31. Hazebroek, M.R.; Moors, S.; Dennert, R.; van den Wijngaard, A.; Krapels, I.; Hoos, M.; Verdonschot, J.; Merken, J.J.; de Vries, B.; Wolffs, P.F., et al. Prognostic Relevance of Gene-Environment Interactions in Patients With Dilated Cardiomyopathy: Applying the MOGE(S) Classification. Journal of the American College of Cardiology 2015, 66, 1313-1323, doi:10.1016/j.jacc.2015.07.023.

32. Lynch, T.L.t.; Ismahil, M.A.; Jegga, A.G.; Zilliox, M.J.; Troidl, C.; Prabhu, S.D.; Sadayappan, S. Cardiac inflammation in genetic dilated cardiomyopathy caused by MYBPC3 mutation. Journal of molecular and cellular cardiology 2017, 102, 83-93, doi:10.1016/j.yjmcc.2016.12.002.

33. Felix, S.B.; Beug, D.; Dorr, M. Immunoadsorption therapy in dilated cardiomyopathy. Expert Rev Cardiovasc Ther 2015, 13, 145152, doi:10.1586/14779072.2015.990385.

34. Paulus, W.J.; Tschope, C. A novel paradigm for heart failure with preserved ejection fraction: comorbidities drive myocardial dysfunction and remodeling through coronary microvascular endothelial inflammation. Journal of the American College of Cardiology 2013, 62, 263-271, doi:10.1016/j.jacc.2013.02.092.

35. Glezeva, N.; Voon, V.; Watson, C.; Horgan, S.; McDonald, K.; Ledwidge, M.; Baugh, J. Exaggerated inflammation and monocytosis associate with diastolic dysfunction in heart failure with preserved ejection fraction: evidence of M2 macrophage activation in disease pathogenesis. Journal of cardiac failure 2015, 21, 167-177, doi:10.1016/j.cardfail.2014.11.004.

36. Verma, S.K.; Krishnamurthy, P.; Barefield, D.; Singh, N.; Gupta, R.; Lambers, E.; Thal, M.; Mackie, A.; Hoxha, E.; Ramirez, V., et al. Interleukin-10 treatment attenuates pressure overload-induced hypertrophic remodeling and improves heart function via signal transducers and activators of transcription 3-dependent inhibition of nuclear factor-kappaB. Circulation 2012, 126, 418429, doi:10.1161/CIRCULATIONAHA.112.112185.

37. Mortensen, R.M. Immune cell modulation of cardiac remodeling. Circulation 2012, 125, 1597-1600, doi:10.1161/CIRCULATIONAHA.112.097832.

38. Anzai, A.; Anzai, T.; Nagai, S.; Maekawa, Y.; Naito, K.; Kaneko, H.; Sugano, Y.; Takahashi, T.; Abe, H.; Mochizuki, S., et al. Regulatory role of dendritic cells in postinfarction healing and left ventricular remodeling. Circulation 2012, 125, 1234-1245, doi:10.1161/CIRCULATIONAHA.111.052126.

39. Laroumanie, F.; Douin-Echinard, V.; Pozzo, J.; Lairez, O.; Tortosa, F.; Vinel, C.; Delage, C.; Calise, D.; Dutaur, M.; Parini, A., et al. CD4+ T cells promote the transition from hypertrophy to heart failure during chronic pressure overload. Circulation 2014, 129, 2111-2124, doi:10.1161/CIRCULATIONAHA.113.007101.

40. Nevers, T.; Salvador, A.M.; Grodecki-Pena, A.; Knapp, A.; Velazquez, F.; Aronovitz, M.; Kapur, N.K.; Karas, R.H.; Blanton, R.M.; Alcaide, P. Left Ventricular T-Cell Recruitment Contributes to the Pathogenesis of Heart Failure. Circulation. Heart failure 2015, 8, 776-787, doi:10.1161/CIRCHEARTFAILURE.115.002225.

41. Fine, N.; Dimitriou, I.D.; Rottapel, R. Go with the flow: GEF-H1 mediated shear stress mechanotransduction in neutrophils. Small GTPases 2020, 11, 23-31, doi:10.1080/21541248.2017.1332505.

42. Kallikourdis, M.; Martini, E.; Carullo, P.; Sardi, C.; Roselli, G.; Greco, C.M.; Vignali, D.; Riva, F.; Ormbostad Berre, A.M.; Stolen, T.O., et al. T cell costimulation blockade blunts pressure overload-induced heart failure. Nature communications 2017, 8, 14680, doi:10.1038/ncomms14680. 
43. Shi, Y.; Zhang, J.; Mullin, M.; Dong, B.; Alberts, A.S.; Siminovitch, K.A. The mDial formin is required for neutrophil polarization, migration, and activation of the LARG/RhoA/ROCK signaling axis during chemotaxis. Journal of immunology 2009, 182, 38373845, doi:10.4049/jimmunol.0803838.

44. Chen, W.; Ghobrial, R.M.; Li, X.C.; Kloc, M. Inhibition of RhoA and mTORC2/Rictor by Fingolimod (FTY720) induces p21activated kinase 1, PAK-1 and amplifies podosomes in mouse peritoneal macrophages. Immunobiology 2018, 223, 634-647, doi:10.1016/j.imbio.2018.07.009.

45. Francis, S.A.; Shen, X.; Young, J.B.; Kaul, P.; Lerner, D.J. Rho GEF Lsc is required for normal polarization, migration, and adhesion of formyl-peptide-stimulated neutrophils. Blood 2006, 107, 1627-1635, doi:10.1182/blood-2005-03-1164.

46. Miyamoto, S.; Del Re, D.P.; Xiang, S.Y.; Zhao, X.; Florholmen, G.; Brown, J.H. Revisited and revised: is RhoA always a villain in cardiac pathophysiology? Journal of cardiovascular translational research 2010, 3, 330-343, doi:10.1007/s12265-010-9192-8.

47. Pulinilkunnil, T.; An, D.; Ghosh, S.; Qi, D.; Kewalramani, G.; Yuen, G.; Virk, N.; Abrahani, A.; Rodrigues, B. Lysophosphatidic acid-mediated augmentation of cardiomyocyte lipoprotein lipase involves actin cytoskeleton reorganization. Am J Physiol Heart Circ Physiol 2005, 288, H2802-2810, doi:10.1152/ajpheart.01162.2004.

48. Siehler, S. Regulation of RhoGEF proteins by G12/13-coupled receptors. British journal of pharmacology 2009, 158, 41-49, doi:10.1111/j.1476-5381.2009.00121.x.

49. Pixley, F.J.; Xiong, Y.; Yu, R.Y.; Sahai, E.A.; Stanley, E.R.; Ye, B.H. BCL6 suppresses RhoA activity to alter macrophage morphology and motility. J Cell Sci 2005, 118, 1873-1883, doi:10.1242/jcs.02314.

50. Hanley, P.J.; Xu, Y.; Kronlage, M.; Grobe, K.; Schon, P.; Song, J.; Sorokin, L.; Schwab, A.; Bahler, M. Motorized RhoGAP myosin $\mathrm{IXb}(\mathrm{Myo} 9 \mathrm{~b})$ controls cell shape and motility. Proceedings of the National Academy of Sciences of the United States of America 2010, 107, 12145-12150, doi:10.1073/pnas.0911986107.

51. Kim, G.D.; Das, R.; Goduni, L.; McClellan, S.; Hazlett, L.D.; Mahabeleshwar, G.H. Kruppel-like Factor 6 Promotes Macrophagemediated Inflammation by Suppressing B Cell Leukemia/Lymphoma 6 Expression. The Journal of biological chemistry 2016, 291, 21271-21282, doi:10.1074/jbc.M116.738617.

52. Troncone, E.; Marafini, I.; Stolfi, C.; Monteleone, G. Transforming Growth Factor-beta1/Smad7 in Intestinal Immunity, Inflammation, and Cancer. Front Immunol 2018, 9, 1407, doi:10.3389/fimmu.2018.01407.

53. Kim, J.S.; Kim, J.G.; Moon, M.Y.; Jeon, C.Y.; Won, H.Y.; Kim, H.J.; Jeon, Y.J.; Seo, J.Y.; Kim, J.I.; Kim, J., et al. Transforming growth factor-beta1 regulates macrophage migration via RhoA. Blood 2006, 108, 1821-1829, doi:10.1182/blood-2005-10-009191.

54. Vargas, P.; Maiuri, P.; Bretou, M.; Saez, P.J.; Pierobon, P.; Maurin, M.; Chabaud, M.; Lankar, D.; Obino, D.; Terriac, E., et al. Innate control of actin nucleation determines two distinct migration behaviours in dendritic cells. Nat Cell Biol 2016, 18, 43-53, doi:10.1038/ncb3284.

55. Wang, Z.; Kumamoto, Y.; Wang, P.; Gan, X.; Lehmann, D.; Smrcka, A.V.; Cohn, L.; Iwasaki, A.; Li, L.; Wu, D. Regulation of immature dendritic cell migration by RhoA guanine nucleotide exchange factor Arhgef5. The Journal of biological chemistry 2009, 284, 28599-28606, doi:10.1074/jbc.M109.047282.

56. Xu, Y.; Pektor, S.; Balkow, S.; Hemkemeyer, S.A.; Liu, Z.; Grobe, K.; Hanley, P.J.; Shen, L.; Bros, M.; Schmidt, T., et al. Dendritic cell motility and $\mathrm{T}$ cell activation requires regulation of Rho-cofilin signaling by the Rho-GTPase activating protein myosin IXb. Journal of immunology 2014, 192, 3559-3568, doi:10.4049/jimmunol.1300695.

57. Nitschke, M.; Aebischer, D.; Abadier, M.; Haener, S.; Lucic, M.; Vigl, B.; Luche, H.; Fehling, H.J.; Biehlmaier, O.; Lyck, R., et al. Differential requirement for ROCK in dendritic cell migration within lymphatic capillaries in steady-state and inflammation. Blood 2012, 120, 2249-2258, doi:10.1182/blood-2012-03-417923.

58. Chacon-Martinez, C.A.; Kiessling, N.; Winterhoff, M.; Faix, J.; Muller-Reichert, T.; Jessberger, R. The switch-associated protein 70 (SWAP-70) bundles actin filaments and contributes to the regulation of F-actin dynamics. The Journal of biological chemistry 2013, 288, 28687-28703, doi:10.1074/jbc.M113.461277.

59. Seul, H.J.; Ahn, Y.R.; Song, H.M.; Ha, Y.J.; Lee, J.R. Over-expression of a RhoA-specific guanine nucleotide exchange factor, p190RhoGEF, in mouse dendritic cells negatively regulates cellular responses to bacterial lipopolysaccharide. Mol Cells 2012, 34, 159-164, doi:10.1007/s10059-012-0055-9.

60. Pollock, J.K.; Verma, N.K.; O'Boyle, N.M.; Carr, M.; Meegan, M.J.; Zisterer, D.M. Combretastatin (CA)-4 and its novel analogue CA-432 impair T-cell migration through the Rho/ROCK signalling pathway. Biochem Pharmacol 2014, 92, 544-557, doi:10.1016/j.bcp.2014.10.002.

61. Moalli, F.; Ficht, X.; Germann, P.; Vladymyrov, M.; Stolp, B.; de Vries, I.; Lyck, R.; Balmer, J.; Fiocchi, A.; Kreutzfeldt, M., et al. The Rho regulator Myosin IXb enables nonlymphoid tissue seeding of protective CD8(+) T cells. The Journal of experimental medicine 2018, 215, 1869-1890, doi:10.1084/jem.20170896.

62. Vicente-Manzanares, M.; Rey, M.; Perez-Martinez, M.; Yanez-Mo, M.; Sancho, D.; Cabrero, J.R.; Barreiro, O.; de la Fuente, H.; Itoh, K.; Sanchez-Madrid, F. The RhoA effector mDia is induced during T cell activation and regulates actin polymerization and cell migration in T lymphocytes. Journal of immunology 2003, 171, 1023-1034, doi:10.4049/jimmunol.171.2.1023.

63. Heasman, S.J.; Carlin, L.M.; Cox, S.; Ng, T.; Ridley, A.J. Coordinated RhoA signaling at the leading edge and uropod is required for T cell transendothelial migration. J Cell Biol 2010, 190, 553-563, doi:10.1083/jcb.201002067.

64. Vielkind, S.; Gallagher-Gambarelli, M.; Gomez, M.; Hinton, H.J.; Cantrell, D.A. Integrin regulation by RhoA in thymocytes. Journal of immunology 2005, 175, 350-357, doi:10.4049/jimmunol.175.1.350.

65. Ocana-Morgner, C.; Wahren, C.; Jessberger, R. SWAP-70 regulates RhoA/RhoB-dependent MHCII surface localization in dendritic cells. Blood 2009, 113, 1474-1482, doi:10.1182/blood-2008-04-152587. 
66. Ocana-Morgner, C.; Gotz, A.; Wahren, C.; Jessberger, R. SWAP-70 restricts spontaneous maturation of dendritic cells. Journal of immunology 2013, 190, 5545-5558, doi:10.4049/jimmunol.1203095.

67. Swat, W.; Fujikawa, K. The Vav family: at the crossroads of signaling pathways. Immunol Res 2005, 32, 259-265, doi:10.1385/IR:32:1-3:259.

68. Goodfellow, H.S.; Frushicheva, M.P.; Ji, Q.; Cheng, D.A.; Kadlecek, T.A.; Cantor, A.J.; Kuriyan, J.; Chakraborty, A.K.; Salomon, A.; Weiss, A. The catalytic activity of the kinase ZAP-70 mediates basal signaling and negative feedback of the T cell receptor pathway. Sci Signal 2015, 8, ra49, doi:10.1126/scisignal.2005596.

69. Helms, W.S.; Jeffrey, J.L.; Holmes, D.A.; Townsend, M.B.; Clipstone, N.A.; Su, L. Modulation of NFAT-dependent gene expression by the RhoA signaling pathway in T cells. J Leukoc Biol 2007, 82, 361-369, doi:10.1189/jlb.0206120.

70. Saci, A.; Carpenter, C.L. RhoA GTPase regulates B cell receptor signaling. Mol Cell 2005, 17, 205-214, doi:10.1016/j.molcel.2004.12.012.

71. Cortes, J.R.; Ambesi-Impiombato, A.; Couronne, L.; Quinn, S.A.; Kim, C.S.; da Silva Almeida, A.C.; West, Z.; Belver, L.; Martin, M.S.; Scourzic, L., et al. RHOA G17V Induces T Follicular Helper Cell Specification and Promotes Lymphomagenesis. Cancer Cell 2018, 33, 259-273 e257, doi:10.1016/j.ccell.2018.01.001.

72. Fujisawa, M.; Sakata-Yanagimoto, M.; Nishizawa, S.; Komori, D.; Gershon, P.; Kiryu, M.; Tanzima, S.; Fukumoto, K.; Enami, T.; Muratani, M., et al. Activation of RHOA-VAV1 signaling in angioimmunoblastic T-cell lymphoma. Leukemia 2018, 32, 694-702, doi:10.1038/leu.2017.273.

73. Leong, D.; Aghel, N.; Hillis, C.; Siegal, D.; Karampatos, S.; Rangarajan, S.; Pond, G.; Seow, H. Tyrosine kinase inhibitors in chronic myeloid leukaemia and emergent cardiovascular disease. Heart 2021, 10.1136/heartjnl-2020-318251, doi:10.1136/heartjnl2020-318251.

74. Amin, E.; Dubey, B.N.; Zhang, S.C.; Gremer, L.; Dvorsky, R.; Moll, J.M.; Taha, M.S.; Nagel-Steger, L.; Piekorz, R.P.; Somlyo, A.V., et al. Rho-kinase: regulation, (dys)function, and inhibition. Biol Chem 2013, 394, 1399-1410, doi:10.1515/hsz-2013-0181. 